\title{
Value of Thrombus CT Characteristics in Patients with Acute Ischemic Stroke
}

(D). Borst, (D).A. Berkhemer, (DE.M.M. Santos, (D) A.J. Yoo, (D). den Blanken, (D).B.W.E.M. Roos, (DE. van Bavel, (DW.H. van Zwam, (D).J. van Oostenbrugge, (D) H.F. Lingsma, (D)A. van der Lugt, (DD.W.J. Dippel, (D)H.A. Marquering, and (DC.B.L.M. Majoie; on behalf of the MR CLEAN investigators

\begin{abstract}
BACKGROUND AND PURPOSE: Thrombus CT characteristics might be useful for patient selection for intra-arterial treatment. Our objective was to study the association of thrombus CT characteristics with outcome and treatment effect in patients with acute ischemic stroke.
\end{abstract}

MATERIALS AND METHODS: We included 199 patients for whom thin-section NCCT and CTA within 30 minutes from each other were available in the Multicenter Randomized Clinical Trial of Endovascular Treatment for Acute ischemic stroke in the Netherlands (MR CLEAN) study. We assessed the following thrombus characteristics: location, distance from ICA terminus to thrombus, length, volume, absolute and relative density on NCCT, and perviousness. Associations of thrombus characteristics with outcome were estimated with univariable and multivariable ordinal logistic regression as an OR for a shift toward better outcome on the mRS. Interaction terms were used to investigate treatment-effect modification by thrombus characteristics.

RESULTS: In univariate analysis, only the distance from the ICA terminus to the thrombus, length of $>8 \mathrm{~mm}$, and perviousness were associated with functional outcome. Relative thrombus density on CTA was independently associated with functional outcome with an adjusted common OR of 1.21 per $10 \%(95 \% \mathrm{Cl}, 1.02-1.43 ; P=.029)$. There was no treatment-effect modification by any of the thrombus $C T$ characteristics.

CONCLUSIONS: In our study on patients with large-vessel occlusion of the anterior circulation, CT thrombus characteristics appear useful for predicting functional outcome. However, in our study cohort, the effect of intra-arterial treatment was independent of the thrombus CT characteristics. Therefore, no arguments were provided to select patients for intra-arterial treatment using thrombus CT characteristics.

ABBREVIATIONS: DT = distance from the ICA terminus to the thrombus; IAT = intra-arterial treatment; ICA-T = ICA terminus; IQR = interquartile range; $M R$ CLEAN = Multicenter Randomized Clinical Trial of Endovascular Treatment for Acute ischemic stroke in the Netherlands

ntra-arterial treatment (IAT) of acute ischemic stroke with retrievable stents for patients with a confirmed intracranial arterial occlusion of the anterior circulation has proved beneficial and

Received September 19, 2016; accepted after revision May 6, 2017.

From the Departments of Radiology (J.B., O.A.B., E.M.M.S., H.A.M., C.B.L.M.M.), Neurology (Y.B.W.E.M.R.), and Biomedical Engineering and Physics (E.M.M.S., M.d.B., E.v.B., H.A.M.), Academic Medical Center, Amsterdam, the Netherlands; Departments of Radiology (W.H.v.Z.) and Neurology (R.J.v.O.), Cardiovascular Research Institute Maastricht, Maastricht University Medical Center, Maastricht, the Netherlands; Departments of Public Health (H.F.L.), Radiology (E.M.M.S., A.v.d.L.), Medical Informatics (E.M.M.S.), and Neurology (O.A.B., D.W.J.D.), Erasmus MC, University Medical Center, Rotterdam, the Netherlands; and Department of Radiology (A.J.Y.), Texas Stroke Institute, Plano, Texas.

This work was supported by the Information Technology for European Advancement 2 project, label ITEA 10004: Medical Distributed Utilization of Services and Applications. The MR CLEAN trial is supported by the Dutch Heart Foundation and by unrestricted grants from Angiocare BV, Covidien/ev3, Medac/Lamepro, and Penumbra. Philips Healthcare provided a workstation with Brain CT Perfusion software (Philips IntelliSpace, version 7.0, Brain CT Perfusion Package); Hester F. Lingsma receives funding from the European Union Seventh Framework Programme safe in multiple randomized controlled trials. ${ }^{1-5}$ Several studies have found a relation between radiologic imaging characteristics of the thrombus and functional outcome, which might have value in the prediction of the efficacy of IAT. For example, multiple studies have suggested that patients with a clot longer than $8 \mathrm{~mm}$ on NCCT do not respond well to IV alteplase but might profit from IAT. ${ }^{6,7}$ Furthermore, a previous study observed that com-

(FP7/2007-2013) under grant agreement No. 602150 (CENTER-TBI; https://www.center-tbi.eu/).

Jordi Borst, Olvert A. Berkhemer, Emile M.M. Santos contributed equally to this work. Henk A. Marquering and Charles B.L.M. Majoie contributed equally to this work.

Please address correspondence to Jordi Borst, MD, Department of Radiology, G1229, Academic Medical Center Amsterdam, Meibergdreef 9, 1105AZ Amsterdam, the Netherlands; e-mail: j.borst@amc.uva.nl

-- Indicates open access to non-subscribers at www.ajnr.org

三 Indicates article with supplemental on-line tables.

http://dx.doi.org/10.3174/ajnr.A5331 


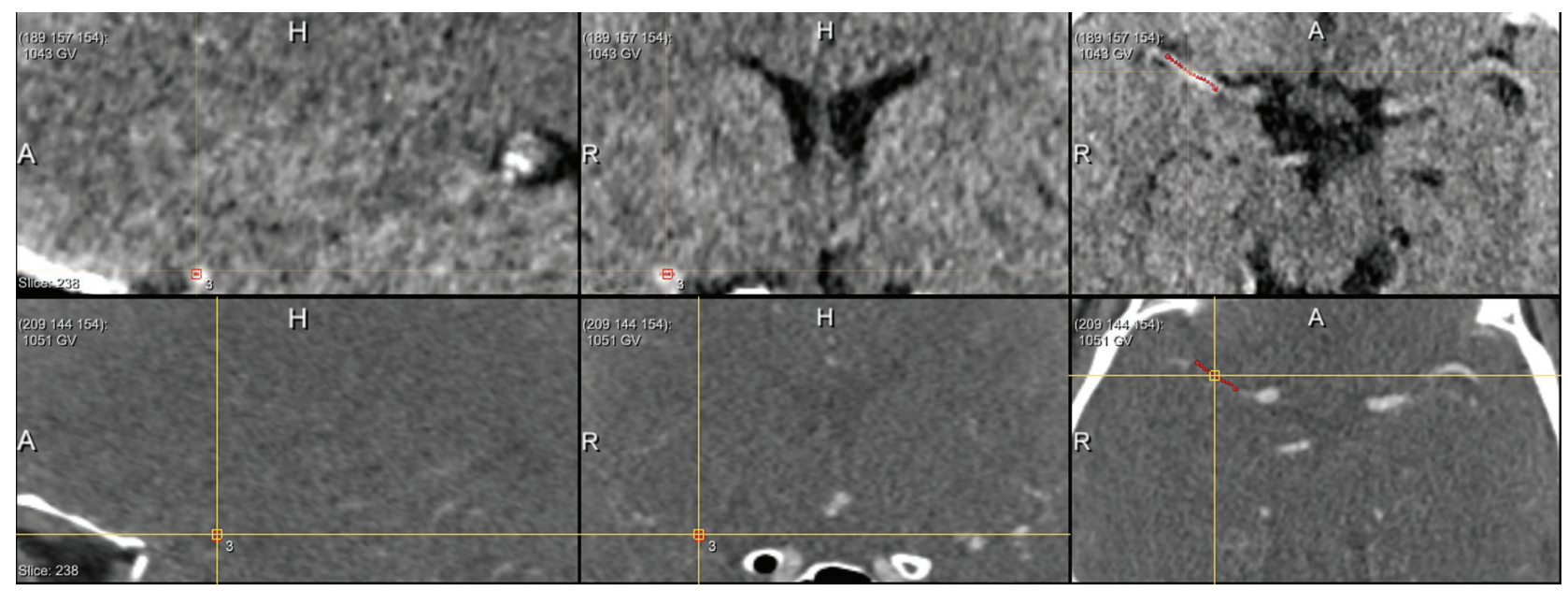

FIG 1. Length measurement. Placement of seed points in the thrombus by the observer. Subsequently, the software determined the centerline through the thrombus, which represents the length of the thrombus. Top row from left to right: sagittal view NCCT, coronal view NCCT, axial view NCCT. Bottom row from left to right: sagittal view CTA, coronal view CTA, axial view CTA.

pared with IV alteplase alone, IAT after IV alteplase leads to better outcomes in patients with a distance from the ICA terminus (ICA-T) to the thrombus (DT) shorter than $16 \mathrm{~mm} .{ }^{8}$ Also, it was found that a thrombus with higher absolute or relative Hounsfield units on NCCT is predictive of successful recanalization with mechanical thrombectomy or intravenous alteplase. ${ }^{9-12}$ Moreover, it was recently shown that thrombus perviousness, which is a measure of the amount of contrast penetration in the thrombus on CTA, is strongly associated with functional outcome. ${ }^{13}$ On the basis of these observations, we hypothesized that thrombus CT characteristics have the potential to be used for selection of patients who are likely to benefit from IAT. We aimed to determine which thrombus CT characteristics are associated with functional outcome in patients with acute ischemic stroke due to a proximal intracranial occlusion enrolled in the Multicenter Randomized Clinical Trial of Endovascular Treatment for Acute ischemic stroke in the Netherlands (MR CLEAN) study. Moreover, we aimed to determine whether the efficacy of IAT on functional outcome was modified by the thrombus CT characteristics.

\section{MATERIALS AND METHODS \\ Patient Selection}

All patients enrolled in MR CLEAN with thin-section $(\leq 2.5 \mathrm{~mm})$ baseline NCCT and CTA acquired within 30 minutes from each other on the same scanner were included in this study $(n=233)$. CT data with too much noise $(n=8)$, severe motion artifacts $(n=$ $22)$, insufficient contrast on CTA $(n=1)$, and incomplete ROI $(n=3)$ were excluded; thus, data from 199 patients were available for further analysis. In MR CLEAN, the effect of IAT versus best medical treatment, including IV alteplase, was investigated in patients with acute ischemic stroke. Patients enrolled in MR CLEAN had a proximal intracranial arterial occlusion of the anterior circulation confirmed on vessel imaging. Permission of the ethics committee and institutional review board was given, and patients or their legal representatives signed informed consents. The protocol and a detailed description of the methods of MR CLEAN have been published previously. ${ }^{14}$

\section{Image Analysis}

We determined the following thrombus characteristics on baseline NCCT and CTA imaging: location, DT, length, volume, absolute and relative attenuation on NCCT, and thrombus perviousness measures: absolute and relative density on CTA, attenuation increase, and void fraction. ${ }^{13}$ Location of the thrombus (M1, M2, A1, A2, ICA, or ICA-T) was determined on CTA by expert neuroradiologists. ${ }^{1}$ The length of the thrombus was measured on NCCT with the aid of coregistered CTA, with an inhouse-developed MeVisLab interface (www.mevislab.de). ${ }^{15} \mathrm{~A}$ trained user (J.B., with 3 years of experience in neuroimaging research), blinded to clinical information, placed several seed points in the thrombus (Fig 1). Subsequently, the software determined the centerline through the thrombus. If needed, the user could adapt the centerline on multiplanar reformations. The length of the thrombus was represented by the length of this centerline. With the same program, the DT was measured by placing several seed points starting in the ICA-T to the proximal border of the thrombus (Fig 2). The volume of the thrombus was calculated with a semiautomated segmentation method adapted from Santos et al. ${ }^{15}$ The centerline already determined for the length measurement was subsequently used in the volume calculation.

Density measurement of the thrombus and contralateral vessel segment was performed on NCCT and coregistered CTA by a trained observer (M.d.B., with 1 year of experience), blinded to clinical information, with the in-house-developed MeVisLab interface. ${ }^{13}$ The mean thrombus density was calculated by averaging the Hounsfield units of 3 manually placed ROIs of the thrombus. Relative density was calculated by dividing the mean Hounsfield unit of the thrombus by the mean Hounsfield unit of the contralateral vessel segment. ${ }^{11}$

We included thrombus perviousness measures estimating the permeability by quantifying the contrast agent penetration in the thrombus on CTA. Absolute and relative thrombus densities on CTA were derived in a manner similar to that of the density measurement on NCCT. Attenuation increase was determined by subtracting the mean density of the thrombus on NCCT from the 


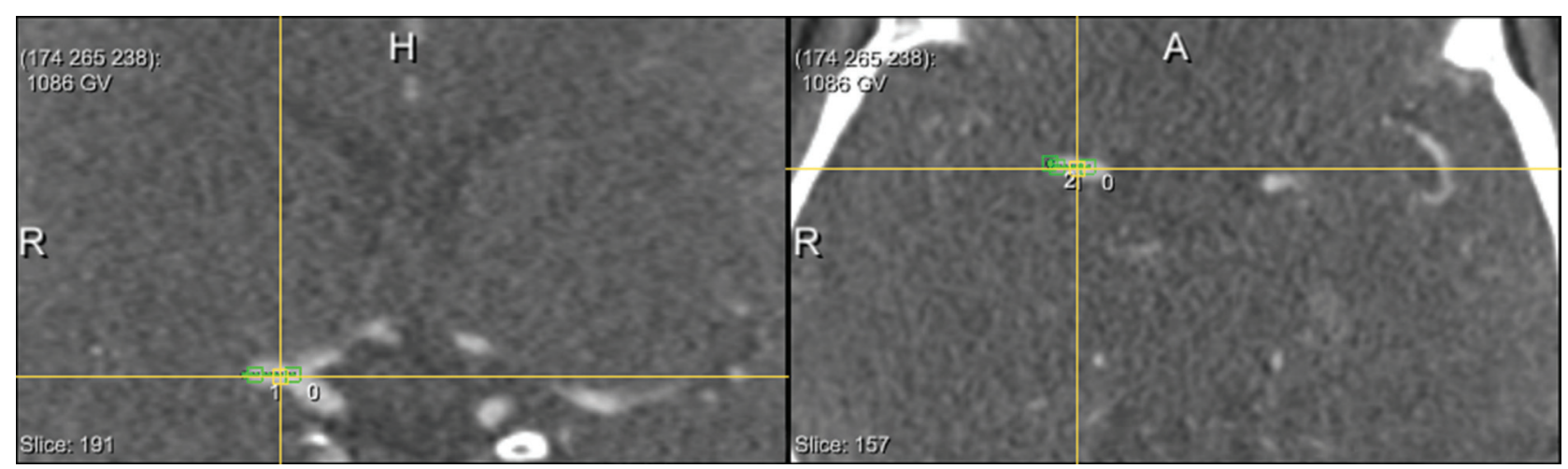

FIG 2. Distance from the ICA-T to the thrombus. Placement of seed points in the vessel from the ICA-T to the thrombus by the observer. Subsequently, the software determined the centerline through the vessel, which represents the distance from the ICA-T to the thrombus. Left: coronal view CTA. Right: axial view CTA.

mean density on CTA. Void fraction was the ratio between the attenuation increase of the thrombus and the attenuation increase of the contralateral vessel segment. ${ }^{13}$

\section{Statistical Analysis}

Association with Outcome. The primary outcome measure was the full modified Rankin Scale score at 90 days. The mRS is an ordered categoric scale to measure functional disability, ranging from 0 (no symptoms) to 6 (death). A score of $\leq 2$ indicates functional independence. ${ }^{16}$ The association of thrombus characteristics with functional outcome was estimated with univariable and multivariable ordinal logistic regression and was presented as a common OR for a shift in the direction of a better outcome on the mRS. ${ }^{16,17}$ The common odds ratio measured the likelihood that the presence of a certain thrombus characteristic would lead to lower modified Rankin Scale scores, compared with the absence of this thrombus characteristic (shift analysis). ${ }^{17}$

If one analyzes the mRS on an ordinal scale, the ordinal nature of the mRS is preserved; therefore, the statistical power is increased compared with dichotomized analyses. ${ }^{18}$

We adjusted for differences in patient characteristics by including the following baseline characteristics as covariates in the multivariable analysis: age, sex, atrial fibrillation, diabetes mellitus, time from onset to randomization, previous stroke, and stroke severity assessed by the NIHSS. We included all thrombus characteristics with a $P$ value $<.10$ (in the univariable analysis) in the multivariable analysis.

To avoid multicollinearity, we implemented thrombus characteristics that were more than moderately correlated with each other (Spearman correlation or point-biserial correlation of $>0.5$ ) in separate models. Of the correlated characteristics, we first included the characteristics with the lowest univariable $P$ value in the multivariable model. Subsequently, we alternately replaced a correlated characteristic for the others in the multivariable model.

Location of the thrombus (ICA-T, $n=46$; M1, $n=131$; M2, $n=22$ ) was dichotomized as an ICA-T occlusion versus a nonICA-T occlusion. Because it has been suggested that patients with a thrombus of $>8 \mathrm{~mm}$ or a DT of $<16 \mathrm{~mm}$ do not respond well to intravenous alteplase, ${ }^{6-8}$ we have also introduced the dichoto- mized thrombus length of $>8 \mathrm{~mm}$ and the DT of $<16 \mathrm{~mm}$ in the analysis.

Secondary outcome measures were the following: the absence of an intracranial occlusion on follow-up CTA and final infarct volume on follow-up NCCT. ${ }^{19}$ For the patients who underwent successful IAT reperfusion, modified Thrombolysis in Cerebral Infarction $2 \mathrm{~B}$ or $3^{20}$ was also used as a secondary outcome measure. For dichotomized outcome measures, univariable logistic regression analysis was performed, and the association was presented as an OR. For final infarct volume, univariable linear regression was performed, and the association was reported as $\mathrm{B}$ coefficients. The multivariable analysis to determine the association of the thrombus characteristics with final infarct volume or absence of occlusion on follow-up CTA was performed, similar to the multivariable analysis for the mRS.

Treatment-Effect Modification. We investigated whether thrombus characteristics had a treatment-effect modification by analyzing whether there was interaction with treatment allocation in the prediction of functional outcome, using a multivariable ordinal logistic regression model, including the thrombus characteristic of interest, treatment allocation, and the multiplicative interaction term of these variables. We also included the baseline characteristics and thrombus characteristics with a univariable $P$ value $<.1$ in a multivariable ordinal logistic regression model. Of the correlated characteristics, we included only the thrombus characteristics with the lowest univariable $P$ value in the multivariable model.

The effect of outliers was minimized by truncation of continuous CT thrombus characteristics (length, volume, DT, absolute and relative density on NCCT, and perviousness) at the 2.5 th and 97.5th percentiles. ${ }^{21}$ STATA/SE 13.1 (StataCorp, College Station Texas) was used for all statistical analyses.

\section{RESULTS}

The mean age was 65 years (range, 31-93 years), and 62\% (124/ 199) were men. Table 1 shows the baseline characteristics of the study cohort, and Table 2 shows the baseline characteristics stratified by treatment. Except for the percentage of patients allocated to IAT, the baseline characteristics of the full MR CLEAN cohort and this study cohort were similar. In our study cohort, 39\% 
Table 1: Baseline characteristics of the full MR CLEAN cohort and subgroups included and not included in this study

\begin{tabular}{|c|c|c|c|}
\hline & $\begin{array}{l}\text { MR CLEAN Subgroup } \\
\text { Included }(n=199)\end{array}$ & $\begin{array}{l}\text { MR CLEAN Not } \\
\text { Included }(n=301)\end{array}$ & $\begin{array}{l}\text { MR CLEAN Full } \\
\text { Cohort }(n=500)\end{array}$ \\
\hline Mean age (yr) & 65 (range, 31-93) & 66 (range, 23-96) & 65 (range, 23-96) \\
\hline Male sex (\%) & $62(124 / 199)$ & $56(168 / 301)$ & $58(292 / 500)$ \\
\hline Median NIHSS score & 18 (IQR, 14-22) & 17 (IQR, 15-21) & 18 (IQR, 14-22) \\
\hline Median ASPECTS & 9 (IQR, 8-10) & $9(\mathrm{IQR}, 7-10)$ & 9 (IQR, 8-10) \\
\hline Diabetes mellitus (\%) & $11(21 / 199)$ & $16(47 / 301)$ & $14(68 / 500)$ \\
\hline Atrial fibrillation (\%) & $27(54 / 199)$ & $27(81 / 301)$ & $27(135 / 500)$ \\
\hline Previous stroke (\%) & $10(20 / 199)$ & $11(34 / 301)$ & $11(54 / 500)$ \\
\hline IAT (\%) & $39(78 / 199)$ & $51(155 / 301)$ & $47(233 / 500)$ \\
\hline Median thrombus length $(\mathrm{mm})(n=186)$ & 15.6 (IQR, 10.3-22.2) (range, 4.8-39.5) & & \\
\hline Median thrombus volume $\left(\mathrm{mm}^{3}\right)(n=186)$ & 70.1 (IQR, 49.3-113.3) (range, 6.1-456.7) & & \\
\hline Median distance to thrombus (mm) & $6.4(\mathrm{IQR}, 0.0-13.5)$ (range, 0.0-38.2) & & \\
\hline T-occlusion (\%) & $23(46 / 199)$ & $29(88 / 301)$ & $27(134 / 500)$ \\
\hline Median density thrombus NCCT (HU) & 49.0 (IQR, 44.5-55.4) (range, 33.1-67.8) & & \\
\hline Median relative density thrombus NCCT (\%) & 134.4 (IQR, 116.8-151.7) (range, 65.8-274.4) & & \\
\hline Median density thrombus CTA (HU) & 61.4 (IQR, 52.6-72.1) (range, 38.5-134.3) & & \\
\hline Median relative density thrombus CTA (\%) & 29.8 (IQR, 21.4-40.8) (range, 12.2-94.7) & & \\
\hline Median thrombus attenuation increase (HU) & 11.4 (IQR, 0.1-22.5) (range, -9.9-80.0) & & \\
\hline Median thrombus void fraction (\%) & 6.0 (IQR, 0.08-15.4) (range, -8.9-61.8) & & \\
\hline
\end{tabular}

Table 2: Baseline characteristics of the full MR CLEAN subgroups included in this study stratified by treatment

\begin{tabular}{|c|c|c|}
\hline & IAT $(n=78)$ & Control $(n=121)$ \\
\hline Mean age (yr) & 63 (range, 43-87) & 66 (range, 31-93) \\
\hline Male sex (\%) & $67(52 / 78)$ & $56(72 / 121)$ \\
\hline Median NIHSS & 17 (IQR, 13-21) & 19 (IQR, 14-23) \\
\hline Median ASPECTS & $9(\mathrm{IQR}, 8-10)$ & $9(\mathrm{IQR}, 8-10)$ \\
\hline Diabetes mellitus (\%) & $9(7 / 78)$ & $12(14 / 121)$ \\
\hline Atrial fibrillation (\%) & $22(17 / 78)$ & $31(37 / 121)$ \\
\hline Previous stroke (\%) & $14(11 / 78)$ & $7(9 / 121)$ \\
\hline Median thrombus length $(\mathrm{mm})(n=186)$ & 16.2 (IQR, 11.6-22.0) (range, 4.8-39.5) & 15.2 (IQR, 10.3-22.3) (range, 4.8-39.5) \\
\hline Median thrombus volume $\left(\mathrm{mm}^{3}\right)(n=186)$ & 69.3 (IQR, 51.7-111.9) (range, 6.1-329.0) & 70.9 (IQR, 43.8-115.5) (range, 11.4-456.7) \\
\hline Median distance to thrombus (mm) & $6.8($ IQR, 0.0-12.8) (range, 0.0-38.2) & 6.4 (IQR, 0.0-13.5) (range, 0.0-38.2) \\
\hline T-occlusion (\%) & $26(20 / 78)$ & $21(26 / 121)$ \\
\hline Median density thrombus NCCT (HU) & 49.0 (IQR, 45.2-55.2) (range, 33.1-67.8) & 48.9 (IQR,44.1-55.4) (range, 33.1-67.8) \\
\hline Median relative density thrombus NCCT (\%) & 137.4 (IQR, 116.0-151.4) (range, 84.8-213.0) & 131.2 (IQR, 117.7-151.7) (range, 65.8-274.4) \\
\hline Median density thrombus CTA (HU) & 61.2 (IQR, 53.3-68.7) (range, 38.5-134.3) & 61.9 (IQR, 52.5-75.1) (range, 38.5-134.3) \\
\hline Median relative density thrombus CTA (\%) & 29.6 (IQR, 23.2-37.9) (range, 12.2-94.7) & 29.8 (IQR, 20.5-43.9) (range, 12.5-88.7) \\
\hline Median thrombus attenuation increase (HU) & 12.3 (IQR, 0.74-19.6) (range, -9.9-80.0) & 11.2 (IQR, -0.9-28.5) (range, -9.9-80.0) \\
\hline Median thrombus void fraction (\%) & 5.8 (IQR, 0.99-12.3) (range, -8.9-61.8) & $6.1(\mathrm{IQR},-0.47-16.8)$ (range, -8.9-61.8) \\
\hline
\end{tabular}

(78/199) of the patients underwent IAT compared with $47 \%$ (233/ $500)$ in the MR CLEAN cohort. The successful reperfusion rate was $59 \%$ (115/194). The median thrombus length was $15.6 \mathrm{~mm}$ (interquartile range [IQR], 10.3-22.2 mm), the median DT was $6.4 \mathrm{~mm}$ (IQR, $0.0-13.5 \mathrm{~mm}$ ), and the median density on NCCT was 49.0 HU (IQR, 44.5-55.4 HU). If the thrombus was located in the ICA-T, the DT was $0 \mathrm{~mm}$. In 13 patients, we were unable to determine the length of the thrombus due to lack of contrast in the extracranial ICA.

In this study cohort, $15 \%(30 / 199)$ of the thrombi were $<8$ $\mathrm{mm}$ and $18 \%(35 / 199)$ had a DT $\geq 16 \mathrm{~mm}$. The median relative CTA thrombus density was $29.8 \%$ (IQR, $21.4 \%-40.8 \%$ ), the median thrombus attenuation increase was $11.4 \mathrm{HU}$ (IQR, 0.1-22.5 $\mathrm{HU}$ ), and the median thrombus void fraction was $6.0 \%$ (IQR, $0.08 \%-15.4 \%$ ).

\section{Associations with Outcome}

DT, length of $>8 \mathrm{~mm}$, and the perviousness measures (ie, absolute and relative CTA density, attenuation increase, and void fraction) were associated with functional outcome in the univariable analysis $(P<.05)($ On-line Table 1$)$. Length and length of $>8$ $\mathrm{mm}$, volume and length, DT and DT $<16 \mathrm{~mm}$, DT and the presence of an ICA-T, and the perviousness measures were correlated with each other (see On-line Table 2 for the correlation coefficients). Only relative thrombus density on CTA was an independent predictor of functional outcome in the multivariable analysis, with an adjusted common OR of 1.21 per $10 \%$ (95\% CI, 1.02-1.43) $(P=.029)$ (see On-line Table 1 for adjusted common ORs). Thrombus volume, DT, DT $<16 \mathrm{~mm}$, NCCT thrombus density, and CTA attenuation increase were associated with the absence of an intracranial occlusion on follow-up CTA (On-line Table 1). In the multivariable analysis, none of the thrombus CT characteristics were associated with the absence of intracranial occlusion on follow-up CTA $(P>$.05) (On-line Table 1). Length of $>8 \mathrm{~mm}$, thrombus volume, DT, DT $<16 \mathrm{~mm}$, the presence of ICA-T, NCCT thrombus density, CTA attenuation increase, and void fraction were associated with final infarct volume (On-line Table 1). In the multivariable analysis, none of the thrombus CT characteristics were associated with final infarct volume (On-line Table 1). 


\section{Treatment-Effect Modification}

We observed no significant treatment-effect modification of IAT with any of the thrombus CT characteristics.

\section{DISCUSSION}

In this study cohort of patients with a large-vessel occlusion of the anterior circulation, DT, length of $>8 \mathrm{~mm}$, and the perviousness measures were associated with functional outcome. In our study, only relative density on CTA was associated with functional outcome after adjustment for the baseline patient characteristics and the other thrombus characteristics. We observed that patients with a higher relative thrombus density on CTA had better functional outcome compared with patients with a lower relative thrombus density on CTA. We observed no treatment-effect modification by any of the thrombus CT characteristics. Therefore, this study provides no arguments to select patients for IAT using thrombus CT characteristics.

Our study confirms that DT is associated with functional outcome in univariable analysis. ${ }^{8}$ In this study cohort, the dichotomized thrombus length of $>8 \mathrm{~mm}$ was associated with functional outcome, which is in line with a previous study demonstrating that patients with a thrombus of $\leq 8 \mathrm{~mm}$ have a better outcome after IV alteplase. ${ }^{7}$ We observed that increasing thrombus density on NCCT was associated with persistent occlusion. In contrast, previous studies have shown that lower absolute and relative thrombus densities are associated with persistent occlusion in patients with anterior circulation occlusion (primarily distal M1 and M2) treated with IV alteplase. ${ }^{1,12}$

We observed that the outcome of patients who underwent IAT was not affected by the density of the thrombus, which is in line with the findings of previous studies in which there was no difference in the NCCT density of the thrombus between patients with and without recanalization after thrombectomy. ${ }^{22,23}$ However, several studies using mechanical thrombectomy in a population of patients with large-vessel occlusion observed that recanalization rates were higher for patients with denser thrombi. ${ }^{10,9}$

We measured CT thrombus characteristics on NCCT with the aid of CTA because it was suggested that it is more accurate for low-density thrombi and for patients with high hematocrit levels, which might cause overestimation of the length of the thrombus. ${ }^{24}$ DT was determined on multiplanar reformations; this process gives the user a better impression of the 3D anatomy of the vasculature compared with previous measurements on transversal maximum intensity projections. ${ }^{25}$

There are several limitations. We excluded many patients due to the unavailability of thin-section NCCT $(n=252)$, which is needed for accurate measurement of the thrombus characteristics. ${ }^{26}$ In $19 \%$ of the patients, IV alteplase was administered before CTA; this order could have affected the perviousness measures. However, there was no difference $(P=.26)$ in average perviousness between patients in whom IV alteplase was administered before or after the CTA. Due to pragmatic reasons, thrombus density was measured by a trained observer and not by a radiologist. However, a previous study showed that the density measurements by the trained observers were reproducible and showed very good agreement with those of the experienced radiologists. ${ }^{27}$ In this study, multiple tests were performed without adjusting the
$P$ values. This choice could have resulted in a false significant association between thrombus characteristics and outcome measures or a false significant treatment-effect modification by the thrombus characteristics. However, this study found only a significant independent association between relative thrombus density on CTA and the mRS, which was also significant $(P<.001)$ in the univariable analysis. This makes it less likely that we have falsely rejected a true null hypothesis. Furthermore, all the interaction terms had a $P$ value $>.05$ in the adjusted analysis; therefore, on the basis of a $P$ value of .05 , none of the null hypotheses were rejected. Adjusting the $P$ values would not change our conclusions.

The confidence intervals of the interaction terms between the thrombus characteristics and treatment effect are wide, thus limiting the generalizability of our observation regarding the absence of significant effect modification.

In this study, relative thrombus density on CTA was independently associated with functional outcome. A higher relative thrombus density on CTA means that the contrast penetration in the thrombus is higher; this feature might be a sign of flow through a thrombus and is related to early reperfusion. ${ }^{28,29}$

\section{CONCLUSIONS}

In this study cohort, a higher relative density of the thrombus on CTA was independently associated with better functional outcome in patients with acute ischemic stroke caused by a largevessel occlusion in the anterior circulation. Therefore, CT thrombus characteristics appear useful for predicting functional outcome. However, in patients with a large vessel occlusion of the anterior circulation, the treatment effect of IAT was independent of the thrombus CT characteristics. Therefore, no arguments were provided to select patients for IAT using thrombus CT characteristics.

\section{ACKNOWLEDGMENTS}

List of MR CLEAN investigators and affiliations:

Olvert A. Berkhemer, MD, ${ }^{1,2}$ Puck S.S. Fransen, MD, ${ }^{2,3}$ Debbie Beumer, $\mathrm{MD}^{2,4}$ Lucie A. van den Berg, MD, ${ }^{5}$ Hester F. Lingsma, MD, PhD, ${ }^{7}$ Albert J. Yoo, MD, ${ }^{8}$ Wouter J. Schonewille, MD, ${ }^{9}$ Jan Albert Vos, MD, PhD, ${ }^{10}$ Paul J. Nederkoorn, MD, $\mathrm{PhD},{ }^{5}$ Marieke J.H. Wermer, $\mathrm{MD}, \mathrm{PhD},{ }^{11}$ Marianne A.A. van Walderveen, $\mathrm{MD}, \mathrm{PhD},{ }^{12}$ Julie Staals, $\mathrm{MD}, \mathrm{PhD},{ }^{4}$ Jeannette Hofmeijer, $\mathrm{MD}, \mathrm{PhD},{ }^{13}$ Jacques A. van Oostayen, $\mathrm{MD}, \mathrm{PhD},{ }^{14}$ Geert J. Lycklama à Nijeholt, $\mathrm{MD}, \mathrm{PhD},{ }^{15}$ Jelis Boiten, MD, $\mathrm{PhD},{ }^{16}$ Patrick A. Brouwer, $\mathrm{MD},{ }^{3}$ Bart J. Emmer, $\mathrm{MD}, \mathrm{PhD},{ }^{3}$ Sebastiaan F. de Bruijn, MD, PhD, ${ }^{17}$ Lukas C. van Dijk, MD, ${ }^{18} \mathrm{~L}$. Jaap Kappelle, MD, PhD,${ }^{19}$ Rob H. Lo, MD, ${ }^{20}$ Ewoud J. van Dijk, $\mathrm{MD}, \mathrm{PhD},{ }^{21}$ Joost de Vries, MD, PhD, ${ }^{22}$ Paul L.M. de Kort, MD, $\mathrm{PhD},{ }^{23}$ Jan S.P. van den Berg, MD, $\mathrm{PhD},{ }^{24}$ Boudewijn A.A.M. van Hasselt, MD,${ }^{25}$ Leo A.M. Aerden, MD, $\mathrm{PhD},{ }^{26}$ René J. Dallinga, $\mathrm{MD},{ }^{27}$ Marieke C. Visser, $\mathrm{MD}, \mathrm{PhD},{ }^{28}$ Joseph C.J. Bot, MD, $\mathrm{PhD},{ }^{29}$ Patrick C. Vroomen, MD, PhD, ${ }^{30}$ Omid Eshghi, MD, ${ }^{31}$ Tobien H.C.M.L. Schreuder, MD, ${ }^{32}$ Roel J.J. Heijboer, MD, ${ }^{33}$ Koos Keizer, $\mathrm{MD}, \mathrm{PhD},{ }^{34}$ Alexander V. Tielbeek, $\mathrm{MD}, \mathrm{PhD},{ }^{35}$ Heleen M. den Hertog, MD, PhD, ${ }^{36}$ Dick G. Gerrits, MD, ${ }^{37}$ Renske M. van den Berg-Vos, MD, PhD, ${ }^{38}$ Giorgos B. Karas, MD, ${ }^{39}$ Ewout W. Steyerberg, MD, PhD, ${ }^{7}$ H. Zwenneke Flach, MD, ${ }^{26}$ 
Henk A. Marquering, $\mathrm{PhD},{ }^{40,1}$ Marieke E.S. Sprengers, MD, $\mathrm{PhD},{ }^{1}$ Sjoerd F.M. Jenniskens, MD, PhD ${ }^{41}$ Ludo F.M. Beenen, $\mathrm{MD},{ }^{1}$ René van den Berg, MD, PhD, ${ }^{1}$ Peter J. Koudstaal, MD, $\mathrm{PhD},{ }^{2}$ Wim H. van Zwam, MD, PhD, ${ }^{6}$ Yvo B.W.E.M. Roos, MD, $\mathrm{PhD},{ }^{5}$ Aad van der Lugt, $\mathrm{MD}, \mathrm{PhD},{ }^{3}$ Robert J. van Oostenbrugge, $\mathrm{MD}, \mathrm{PhD},{ }^{4}$ Charles B.L.M. Majoie, $\mathrm{MD}, \mathrm{PhD},{ }^{1}$ and Diederik W.J. Dippel, $\mathrm{MD}, \mathrm{PhD}^{2}$.

1) Department of Radiology, Academic Medical Center Amsterdam, the Netherlands; 2) Department of Neurology, Erasmus MC University Medical Center Rotterdam, the Netherlands; 3) Department of Radiology, Erasmus MC University Medical Center Rotterdam, the Netherlands; 4) Department of Neurology, Maastricht University Medical Center and Cardiovascular Research Institute Maastricht, the Netherlands; 5) Department of Neurology, Academic Medical Center Amsterdam, the Netherlands; 6) Department of Radiology, Maastricht University Medical Center, the Netherlands; 7) Department of Public Health, Erasmus MC University Medical Center Rotterdam, the Netherlands; 8) Department of Radiology, Texas Stroke Institute, Plano, Texas; 9) Department of Neurology, Sint Antonius Hospital, Nieuwegein, the Netherlands; 10) Department of Radiology, Sint Antonius Hospital, Nieuwegein, the Netherlands; 11) Department of Neurology, Leiden University Medical Center, Leiden, the Netherlands; 12) Department of Radiology, Leiden University Medical Center, Leiden, the Netherlands; 13) Department of Neurology, Rijnstate Hospital, Arnhem, the Netherlands; 14) Department of Radiology, Rijnstate Hospital, Arnhem, the Netherlands; 15) Department of Radiology, MC Haaglanden, the Hague, the Netherlands; 16) Department of Neurology, MC Haaglanden, the Hague, the Netherlands; 17) Department of Neurology, HAGA Hospital, the Hague, the Netherlands; 18) Department of Radiology, HAGA Hospital, the Hague, the Netherlands; 19) Department of Neurology, University Medical Center Utrecht, Utrecht, the Netherlands; 20) Department of Radiology, University Medical Center Utrecht, Utrecht, the Netherlands; 21) Department of Neurology, Radboud University Medical Center, Nijmegen, the Netherlands; 22) Department of Neurosurgery, Radboud University Medical Center, Nijmegen, the Netherlands; 23) Department of Neurology, Sint Elisabeth Hospital, Tilburg, the Netherlands; 24) Department of Neurology, Isala Klinieken, Zwolle, the Netherlands; 25) Department of Radiology, Isala Klinieken, Zwolle, the Netherlands; 26) Department of Neurology, Reinier de Graaf Gasthuis, Delft, the Netherlands; 27) Department of Radiology, Reinier de Graaf Gasthuis, Delft, the Netherlands; 28) Department of Neurology, VU Medical Center, Amsterdam, the Netherlands; 29) Department of Radiology, VU Medical Center, Amsterdam, the Netherlands; 30) Department of Neurology, University Medical Center Groningen, Groningen, the Netherlands; 31) Department of Radiology, University Medical Center Groningen, Groningen, the Netherlands; 32) Department of Neurology, Atrium Medical Center, Heerlen, the Netherlands; 33) Department of Radiology, Atrium Medical Center, Heerlen, the Netherlands; 34) Department of Neurology, Catharina Hospital, Eindhoven, the Netherlands; 35) Department of Radiology, Catharina Hospital, Eindhoven, the Netherlands; 36) Department of Neurology, Medical Spectrum Twente, Enschede, the Netherlands; 37) Department of Radiology, Medical Spec- trum Twente, Enschede, the Netherlands; 38) Department of Neurology, Sint Lucas Andreas Hospital, Amsterdam, the Netherlands; 39) Department of Radiology, Sint Lucas Andreas Hospital, Amsterdam, the Netherlands; 40) Department of Biomedical Engineering and Physics, Academic Medical Center Amsterdam, the Netherlands; 41) Department of Radiology, Radboud University Medical Center, Nijmegen, the Netherlands.

Disclosures: Olvert A. Berkhemer-UNRELATED: Payment for Lectures Including Service on Speakers Bureaus: The Academic Medical Center received funds from Stryker for consultations by O.A.B.* Emilie M.M. Santos-UNRELATED: Grant: Stichting voor de technische wetenschappen (STW), Comments: 11632.* Albert J. Yoo-UNRELATED: Consultancy: Neuravi, Comments: core imaging lab activities and directorship; Grants/Grants Pending: Penumbra, Comments: core imaging lab activities. * Wim H. van Zwam-UNRELATED: Consulting Fee or Honorarium: Stryker, Codman Neuro, Comments: modest speaker fees. * Robert J. van OostenbruggeUNRELATED: Board Membership: Medtronic, Comments: member of Data and Safety Monitoring Board of SURTAVI, a cardiointervention trial of valve replacement.* Aad van der Lugt—RELATED: Grant: Dutch Heart Foundation, Angiocare BV, Covidien/ev3 (Medtronic), Medac/Lamepro, Penumbra, Stryker.* Diederik W.J. Dippel-UNRELATED: Board Membership: The MR CLEAN trial was partly funded by the Dutch Heart Foundation and by unrestricted grants from Angiocare BV, Medtronic/ Covidien/ev3, Medac/Lamepro, Penumbra, Stryker, and Top Medical/Concentric*; Consultancy: Erasmus MC received funds from Stryker and Bracco for consultations by D.W.J.D.* Henk A. Marquering-RELATED: Grant: Information Technology for European Advancement 3*; OTHER: cofounder and shareholder of Nico-Lab. Charles B.L.M. Majoie - RELATED: Grant: Dutch Heart Foundation*; Consulting Fee or Honorarium: Dr Majoie's institution (Academic Medical Center) received funds from Stryker for consultations by C.B.L.M.M*; UNRELATED: Grants/Grants Pending: TWIN Foundation*; Payment for Lectures Including Service on Speakers Bureaus: Stryker*. *Money paid to the institution.

\section{REFERENCES}

1. Berkhemer OA, Fransen PS, Beumer D, et al; MR CLEAN Investigators. A randomized trial of intraarterial treatment for acute ischemic stroke. $N$ Engl J Med 2015;372:11-20 CrossRef Medline

2. Campbell BC, Mitchell PJ, Kleinig TJ, et al; EXTEND-IA Investigators. Endovascular therapy for ischemic stroke with perfusion-imaging selection. $N$ Engl J Med 2015;372:1009-18 CrossRef Medline

3. Goyal M, Demchuk AM, Menon BK, et al; ESCAPE Trial Investigators. Randomized assessment of rapid endovascular treatment of ischemic stroke. N Engl J Med 2015;372:1019-30 CrossRef Medline

4. Saver JL, Goyal M, Bonafe A, et al; SWIFT PRIME Investigators. Stent-retriever thrombectomy after intravenous t-PA vs. t-PA alone in stroke. $N$ Engl J Med 2015;372:2285-95 CrossRef Medline

5. Jovin TG, Chamorro A, Cobo E, et al; REVASCAT Trial Investigators. Thrombectomy within $\mathbf{8}$ hours after symptom onset in ischemic stroke. N Engl J Med 2015;372:2296-306 CrossRef Medline

6. Kamalian S, Morais LT, Pomerantz SR, et al. Clot length distribution and predictors in anterior circulation stroke: implications for intra-arterial therapy. Stroke 2013;44:3553-56 CrossRef Medline

7. Riedel CH, Zimmermann P, Jensen-Kondering U, et al. The importance of size: successful recanalization by intravenous thrombolysis in acute anterior stroke depends on thrombus length. Stroke 2011;42:1775-77 CrossRef Medline

8. Lobsien D, Gawlitza M, Schaudinn A, et al. Mechanical thrombectomy versus systemic thrombolysis in MCA stroke: a distance to thrombus-based outcome analysis. J Neurointerv Surg 2016;8: 878-82 CrossRef Medline

9. Mokin M, Morr S, Natarajan SK, et al. Thrombus density predicts successful recanalization with Solitaire stent retriever thrombectomy in acute ischemic stroke. J Neurointerv Surg 2015;7:104-07 CrossRef Medline

10. Moftakhar P, English JD, Cooke DL, et al. Density of thrombus on admission CT predicts revascularization efficacy in large vessel occlusion acute ischemic stroke. Stroke 2013;44:243-45 CrossRef Medline

11. Puig J, Pedraza S, Demchuk A, et al. Quantification of thrombus 
Hounsfield units on noncontrast CT predicts stroke subtype and early recanalization after intravenous recombinant tissue plasminogen activator. AJNR Am J Neuroradiol 2012;33:90-96 CrossRef Medline

12. Niesten JM, van der Schaaf IC, van der Graaf Y, et al. Predictive value of thrombus attenuation on thin-slice non-contrast CT for persistent occlusion after intravenous thrombolysis. Cerebrovasc Dis 2014;37:116-22 CrossRef Medline

13. Santos EM, Marquering HA, den Blanken MD, et al; MR CLEAN Investigators. Thrombus permeability is associated with improved functional outcome and recanalization in patients with ischemic stroke. Stroke 2016;47:732-41 CrossRef Medline

14. Fransen PSS, Beumer D, Berkhemer OA, et al; MR CLEAN Investigators. MR CLEAN, a multicenter randomized clinical trial of endovascular treatment for acute ischemic stroke in the Netherlands: study protocol for a randomized controlled trial. Trials 2014;15:343 CrossRef Medline

15. Santos EM, Marquering HA, Berkhemer OA, et al; MR CLEAN Investigators. Development and validation of intracranial thrombus segmentation on CT angiography in patients with acute ischemic stroke. PLoS One 2014;9:e101985 CrossRef Medline

16. van Swieten JC, Koudstaal PJ, Visser MC, et al. Interobserver agreement for the assessment of handicap in stroke patients. Stroke 1988; 19:604-07 CrossRef Medline

17. Saver JL. Novel end point analytic techniques and interpreting shifts across the entire range of outcome scales in acute stroke trials. Stroke 2007;38:3055-62 CrossRef Medline

18. Nunn A, Bath PM, Gray LJ. Analysis of the modified Rankin scale in randomised controlled trials of acute ischaemic stroke: a systematic review. Stroke Res Treat 2016;2016:9482876 CrossRef Medline

19. Boers AM, Marquering HA, Jochem JJ, et al; MR CLEAN Investigators. Automated cerebral infarct volume measurement in follow-up noncontrast CT scans of patients with acute ischemic stroke. AJNR Am J Neuroradiol 2013;34:1522-27 CrossRef Medline

20. Zaidat OO, Yoo AJ, Khatri P, et al; Cerebral Angiographic Revascularization Grading (CARG) Collaborators, STIR Revascularization Working Group, STIR Thrombolysis in Cerebral Infarction (TICI) Task Force. Recommendations on angiographic revascularization grading standards for acute ischemic stroke: a consensus statement. Stroke 2013;44:2650-63 CrossRef Medline

21. Steyerberg EW. Coding of categorical and contiuous predictors. In: Gail M, Krickeberg K, Samet J, et al, eds. Clinical Prediction Models: A Practical Approach to Development, Validation, and Updating (Statistics for Biology and Health). New York: Springer-Verlag; 2009:159-73 CrossRef

22. Yilmaz U, Roth C, Reith W, et al. Thrombus attenuation does not predict angiographic results of mechanical thrombectomy with stent retrievers. AJNR Am J Neuroradiol 2013;34:2184-86 CrossRef Medline

23. Spiotta AM, Vargas J, Hawk $\mathrm{H}$, et al. Hounsfield unit value and clot length in the acutely occluded vessel and time required to achieve thrombectomy: complications and outcome. J Neurointervent Surg 2014;6:423-27 CrossRef Medline

24. New PF, Aronow S. Attenuation measurements of whole blood and blood fractions in computed tomography. Radiology 1976;121: 635-40 CrossRef Medline

25. Friedrich B, Gawlitza M, Schob S, et al. Distance to thrombus in acute middle cerebral artery occlusion: a predictor of outcome after intravenous thrombolysis for acute ischemic stroke. Stroke 2015;46: 692-96 CrossRef Medline

26. Riedel CH, Jensen $\mathrm{U}$, Rohr A, et al. Assessment of thrombus in acute middle cerebral artery occlusion using thin-slice nonenhanced computed tomography reconstructions. Stroke 2010;41:1659-64 CrossRef Medline

27. Santos EM, Yoo AJ, Beenen LF, et al; MR CLEAN Investigators. Observer variability of absolute and relative thrombus density measurements in patients with acute ischemic stroke. Neuroradiology 2016;58:133-39 CrossRef Medline

28. Mishra SM, Dykeman J, Sajobi TT, et al. Early reperfusion rates with IV tPA are determined by CTA clot characteristics. AJNR Am J Neuroradiol 2014;35:2265-72 CrossRef Medline

29. Frölich AM, Psychogios MN, Klotz E, et al. Antegrade flow across incomplete vessel occlusions can be distinguished from retrograde collateral flow using 4-dimensional computed tomographic angiography. Stroke 2012;43:2974-79 CrossRef Medline 